\title{
Meditsiiniline alkeemia 19. sajandil: elektrohomöopaatia teoreetilised ja praktilised lähtekohad
}

\author{
Kurmo Konsa \\ Kõrgema Kunstikooli Pallas professor ja \\ Tartu Ülikooli kaasprofessor \\ kurmo.konsa@ut.ee
}

\begin{abstract}
Teesid: Meditsiiniline alkeemia tekkis lääne alkeemilise traditsiooni raames 13. ja 14. sajandil. Väljakujunenud meditsiiniliseks alkeemiaks võib aga lugeda 16. sajandil tekkinud iatrokeemiat. Käesolevas artiklis keskendun alkeemiatraditsiooni jätkumisele 19. sajandi teisel poolel, kasutades näitena Cesare Mattei loodud elektrohomöopaatiat. Mattei loodud elektrohomöopaatia küll tugineb homöopaatiale, kuid arendab selle hoopis uuele tasemele. Klassikaline ehk Samuel Hahnemanni õpetusi järgiv homöopaatia kasutab ühte toimeainet sisaldavaid ravimeid. Sellest klassikalisest lähenemisest erinevad nn komplekshomöopaatilised suunad, mis kasutavad liitravimeid. Mattei tugines oma ravisüsteemi loomisel nii homöopaatiale kui ka varasemale alkeemilisele traditsioonile. Samas võttis ta üle omaaegse teaduse ideid ja integreeris neid oma ravisüsteemi. Elektrohomöopaatia on iatrokeemia edasiarendus, tuginedes selgelt oma aja teadustele, ning selles ei ole midagi müstilist ega okultset. Elektrohomöopaatia iseloomustab väga hästi tõsiasja, et alkeemia praktikad ja teooriad muutusid aja jooksul ja kohandusid muutunud kontekstidega. Tegemist on selle väljatöötaja sõnutsi empiirilise ravisüsteemiga, mille korral on väidetavalt esmane ravimite toime katsetamine ja alles selle alusel teooria püstitamine. Tänapäevast elektrohomöopaatiat iseloomustab kasutatavate ravimprepraatide rohkus ja müstiliste seletuste kasutuselevõtt.
\end{abstract}

Märksõnad: alkeemia, Cesare Mattei, elektrohomöopaatia, meditsiiniline alkeemia, spagüürika, taimravi

\section{Sissejuhatus}

Alkeemia kuulub kindlasti nähtuste hulka, millest igaüks on midagi kuulnud, kui ka mitte midagi muud, siis kindlasti seda, et alkeemikud olid need, kes proovisid kulda teha ja otsisid filosoofilist kivi. Igal juhul on tegemist millegi müstilise ja mõistatuslikuga. Kui aga sellised populaarkultuuris levinud seisukohad kõrvale jätta, siis selgub, et tegemist on pika ja keeruka ajalooga kultuurinähtusega, mis ulatub tänasesse päeva välja. 
Alkeemia on alati ühelt poolt olnud seotud ajajärgule iseloomuliku tehnokeemilise praktikaga (alates 17. sajandist juba väljakujunenud keemilise tehnoloogiaga) ning teiselt poolt filosoofiliste ja religioossete vaadetega looduse kohta. Enne 18. sajandit olid alkeemia ja keemia põhimõtteliselt eristamatud, alkeemia pidamine millekski teadusest kardinaalselt erinevaks on hilisem seisukoht. ${ }^{1}$ Sarnaselt tänapäevase keemiaga tegeles alkeemia samuti ainetega, uurides nende omadusi, muutumist ja täiustamise võimalusi. Tegemist oli praktilise teadusega, mille eesmärgiks oli füüsilise maailma ehituse selgitamine. Alkeemia oli väga tihedalt seotud loodusfilosoofia teiste harudega, nagu füüsika, astroloogia ja meditsiin. Võrreldes näiteks loodusfilosoofiaga oli alkeemias alati tähtsal kohal praktiline aspekt. Lisaks autoriteetidele ja aruteludele toetusid alkeemikud vaatlustele ja eksperimentidele. Samas tuleb muidugi rõhutada, et ühtset alkeemilist kaanonit pole kunagi olnud, oma arengu iseärasuste tõttu oli alkeemia märksa vähem standardiseeritud kui näiteks meditsiin või teoloogia (Matus 2017: 1-3).

Meditsiiniline alkeemia tekkis lääne alkeemilise traditsiooni raames 13. ja 14. sajandil. Väljakujunenud meditsiiniliseks alkeemiaks võib aga lugeda 16. sajandil tekkinud iatrokeemiat. Käesolevas artiklis keskendun alkeemiatraditsiooni jätkumisele 19. sajandi teisel poolel, kasutades näitena Cesare Mattei poolt loodud elektrohomöopaatiat. Nagu meetodi nimetus viitab, on see seotud ühelt poolt klassikalise homöopaatiaga. Täiendsõna "elektro" viitab aga hoopiski tema poolt väljatöötatud ravimite elektrilöögi sarnaselt kiirele toimele. Elektrohomöopaatia loomisest ja taustast on senini üsna vähe teada (Blessing 2011: v). Samuti ei ole lähemat käsitlemist leidnud elektrohomöopaatia seosed varasema alkeemiatraditsiooniga. Teaduslikke käsitlusi² elektrohomöopaatia kohta napib, enamik allikaid tegeleb selle meetodi tutvustamise ja propageerimisega.

Mattei elektrohomöopaatia käsitlusele vajaliku konteksti loomiseks kirjeldan esmalt Euroopa alkeemiatraditsiooni, keskendudes meditsiinilisele alkeemiale. Meditsiinilise alkeemiana käsitlen alkeemiliste ideede ja protsesside kasutamist ravimite valmistamiseks ja inimkeha toimimise seletamiseks (Hedesan 2016: xii). Seejärel annan ülevaate Cesare Mattei loodud elektrohomöopaatiast, tuginedes peamiselt tema enda kirjutistele.

Tegemist oli omal ajal vägagi populaarse meetodiga, mis pole oma menu kaotanud ka tänapäeval. Ajalooliste ja ideeliste juurte selgitamine aitab mõista meetodi leviku ja populaarsuse põhjuseid, samuti ametliku meditsiini reaktsiooni sellele. 


\section{Meditsiinilise alkeemia kujunemine}

Alkeemia täpsem määratlemine ei ole sugugi lihtne, kuna tegemist on nähtusega, mis on eksisteerinud pika aja kestel ja väga erinevates kultuurikontekstides (vt Principe \& Newman 2001; Kahn 2007: 7). Laskumata siinkohal tänapäevaste definitsioonide eritlemisse, toon järgnevalt alkeemia määratluse raamatust "Mirror of Alchemy" (Speculum Alchemiae), mille autoriks on ekslikult peetud Roger Baconit. Kõige tõenäolisemalt on selle raamatu kirjutanud keegi anonüümne autor ajavahemikus 13.-15. sajand. Alkeemiat määratleb see tundmatu autor järgmiselt (Bacon 1597: 1):

Paljudest iidsetest raamatutest võib leida selle kunsti määratlusi, mida me käesolevas peatükis kavatseme arvesse võtta. Sest Hermes ütles sellest teadusest: alkeemia on kehaline teadus, koosnedes lihtsalt ühest ja ühevõrra, ühendades loomulikul teel teadmise ja mõju abil kehasid märksa väärtuslikemateks ja muutes neid loomuliku segamise teel paremaks. Keegi teine ütles: alkeemia on teadus, mis õpetab kuidas muuta mistahes metalli teiseks, ning seda tehakse sobiva meditsiini abil, nii nagu see selgub paljude filosoofide raamatutest. Alkeemia on seega teadus, mis õpetab, kuidas valmistada ja ühendada teatud ravimit, mida nimetatakse eliksiiriks, mis siis kui seda valatakse metallidele või ebatäiuslikele kehadele, muudab need täiuslikeks transmutatsiooni käigus.

Nagu toodud lõigust näha, kirjeldab traktaadi autor alkeemiat teadusena, mis käsitleb vähemväärtuslike asjade muutmist enam väärtuslikeks. Kõige ilmsemaks näiteks sellisest transmutatsioonist ongi harilike metallide muutmine väärismetallideks, kuid iseenesest käib see kõikide looduslike kehade kohta. Teaduse kõrval on väga selgelt tegemist ka kunstiga, mis tähendab seda, et transmutatsiooniprotsessi üle mitte ainult ei arutleta teaduslikult, vaid seda ka teostatakse praktiliselt. Selle praktilise poole tõttu on alkeemia olnud seotud metallurgia, kullasepakunsti, juveliirikunsti ja klaasivalamisega. Transmutatsiooni läbiviimiseks kasutatakse "vastavat ravimit" ehk eliksiiri.

Kui käsitleda alkeemia teooriat ja praktikat hästi laialt, nimelt looduses toimuvate muutumisprotsesside uurimise ja mõjutamisena, siis võib eristada kolm suurt alkeemia kultuurilis-geograafilist kujunemiskeskust. Lääne või Euroopa alkeemia sai alguse kreeka-egiptuse kultuuris (ca 3. sajand m.a.j) ning levis Põhja-Aafrikas, Lähis-Idas, Bütsantsis ja Euroopa aladel. Hiina alkeemia on väga tihedalt seotud taoismiga ning see tekkis ajaliselt varem kui lääne alkeemia. India alkeemiline traditsioon on üsna tihedalt seotud Hiina vastavate teooriate ja praktikatega ning see kujunes välja millalgi meie ajajarvamise alguses. ${ }^{3}$ Hiinas ja Indias levinud alkeemilised õpetused ja praktikad erinevad 
siiski nii suurel määral Euroopas kasutusel olnutest, et neid on raske ühise nimetaja alla võtta ning tänapäeva teadlased eelistavad neid väga selgelt eristada. Kui Hiina ja India alkeemias olid kesksed inimese noorendamise, tervise taastamise ja surematuse saavutamisega seotud probleemid, siis Egiptuses ja Euroopas kujunenud alkeemia keskendus looduses toimuvate muutumisprotsesside uurimisel ennekõike metallidele ja keemilistele ainetele.

Alkeemia seostamine meditsiiniga algas Euroopas 13. ja 14. sajandil selliste frantsiskaani mungaordu liikmete nagu Roger Bacon (1214-1294), Arnaldo da Villanova (1235-1311) ja Johannes de Rupescissa (14. sajandi keskpaik) töödes (Debus 2002: 19-25; Moran 2005; Multhauf 1956). Meditsiiniline suund Euroopa alkeemias muutus märksa olulisemaks alles 16. sajandil, mil ilmus nn iatrokeemia. ${ }^{4}$ Iatrokeemia puhul ongi tegemist selgelt meditsiinilise suunitlusega alkeemiaga. Iatrokeemia väljatöötajaks oli Philippus Aureolus Theophrastus Bombastus von Hohenheim (1493-1541), kes on enam tuntud Paracelsuse nime all. Paracelsus toetus suurel määral varastele meditsiinikallakuga alkeemikutele, nagu Johannes de Rupescissa ja pseudo-Llull. ${ }^{5}$ Samas arendas ta välja mitte millegi varasemaga võrreldava kosmoloogilise iatrokeemia. Paracelsuse järgi koosneb kogu maailm (ja kõik kehad) kolmest filosoofilisest põhiprintsiibist: soolast (sal), väävlist (sulphur) ja elavhõbedast (mercurius). Need kolm printsiipi küll erinevad üksteisest, kuid moodustavad kolmese ühtsuse (tria prima). Tegemist ei ole tavapäraste keemiliste ainetega, vaid just nimelt filosoofiliste printsiipidega. Ravimite valmistamisel võttis Paracelsus kasutusele erinevad mineraalsed, taimsed ja loomsed ained ning keemilised meetodid nende töötlemiseks. Erinevalt varasemast humoraalmeditsiinist, mis käsitles haiguseid ennekõike terve keha huumorite tasakaalutusena, rõhutas Paracelsus haiguse asukohta kindlas organis. Ravimeetod pidi vastama konkreetsele haigusele ning ainete raviomadused seostusid mitte nende aristoteleslike kvaliteetidega (külmus-soojus, kuivus-niiskus), vaid keemiliste omadustega. Ravimid toimisid mitte maagia, vaid neile omaste sisemiste omaduste kaudu.

Paracelsus võttis kasutusele ka termini spagüürika (spagyria, spagyric), mis tuleneb kreekakeelsetest sõnadest span (lahuta, eralda) ja ageirein (ühenda, kombineeri). ${ }^{6}$ Nimetus viitab alkeemilisele protsessile, mille käigus lähteained lagundatakse ja seejärel uuesti ühendatakse. Ravimite valmistamisel tähendab see puhta ravitoimega aine eraldamist ebapuhtast mateeriast. Spagüürilisi meetodeid kasutati metallide, mineraalide, loomsete ja taimsete lähteainete puhastamiseks. Esialgu tähistas termin spagüüriline alkeemiat tervikuna, hiljem hakkas tähendama ainult taimedest ravimite valmistamist.

Paracelsuse järgijatest oli üks kuulsamaid kahtlemata flaami arst ja alkeemik Jan Babtist van Helmont (1579-1644). Toetudes alguses Paracelsuse ideedele arendas ta hiljem välja küllaltki originaalse sünteesi kristliku teoloogia 
ja loodusfilosoofia vahel, mis tugines Piiblile ja alkeemiale (Hedesan 2016). Ta eitas Paracelsuse kolme alusprintsiipi ja pidas kõikide looduslike asjade põhiprintsiibiks vett. Samuti tegeles ta metallidest ja mineraalidest ravimite valmistamisega. Van Helmont kasutas meditsiinilise alkeemia tähenduses termineid spagyria, chymia või pyrotechnia. Iatrokeemia arendas välja terviklikuks süsteemiks aga hollandi arst ja anatoom Francois de le Boe Sylvius (1614-1672). ${ }^{7}$ Tema vaadete kohaselt olid kõik eluprotsessid, sealhulgas ka haigused, keemilist päritolu. Keskseks teemaks tema käsitluses on fermenteerimine, mille käigus vabanevad toitained satuvad sapipõie ja lümfisoonte vahendusel verre ning sealtkaudu toidavad kogu keha. Olulisel kohal oli aluseliste ja happeliste laguproduktide tasakaalu mõiste, mille kaudu seletas ta ka haiguste teket. Nagu näha, toetus ta nii Paracelsuse kui ka eelnenud humoraalmeditsiini mõnedele ideedele. Selline meditsiinilis-keemiline lähenemine lõi aluse uute ravimite valmistamisele.

Saksa arst Samuel Hahnemann (1755-1843) lõi 19. sajandi alguses farmakoloogilise süsteemi, mille nimetas homöopaatiaks (kreeka homoion - sarnane). Homöopaatia keskendub keha kaitsemehhanismide stimuleerimisele, mitte otseselt haigusega võitlemisele. Ravimisel kasutatakse sarnasuse printsiipi, mille kohaselt haigust ravitakse ainetega, mis kutsuvad tervel inimesel esile haigusele sarnaseid sümptomeid. ${ }^{8}$ Ravimeid kasutatakse ülilahjendatud kujul. Hahnemann kasutas korraga ühte puhast ainet, hiljem hakkasid homöopaadid välja kirjutama ka ainete segusid ja valmistama kompleksseid ravimeid.

Meditsiinilise alkeemia arendajate hulka kuulusid veel Johann Rudolph Glauber (1604-1670), Johann Gottlieb Rademacher (1752-1850), Carl-Friedrich Zimpel (1801-1879) ning ka elektrohomöopaatia väljatöötaja Cesare Mattei.

\section{Cesare Mattei ja elektrohomöopaatia loomine}

Elektrohomöopaatia, mida tuntakse ka Mattei vähiravi ja matteismi (matteism) nime all, on homöopaatia vorm, mille arendas välja krahv Cesare Mattei (1809-1896) 19. sajandi teisel poolel. Mattei kasvas üles rikkas maaomanike perekonnas Bolognas. ${ }^{9}$ Kuni 19aastaseks saamiseni õppis Bologna seminaris, pärast isa surma päris ta laiaulatuslikud valdused ning suundus Euroopa reisile. 30aastasena, pärast skandaali ja duelli ühe teise Bologna aristokraadiga, toimus ta elus muutus. Ta hakkas suhtlema poeedi ja filosoofi Paolo Costaga (1771-1836) ning asus tema juhatusel õppima ajalugu, filosoofiat, kunstiajalugu ja loodusteadusi. 1840. aastad olid Itaalias keerulised nii sise- kui ka välispoliitiliselt. Austria armee tungis Itaaliasse. Mattei perekond omas maavaldusi strateegiliselt väga olulises piirkonnas Comacchio maakonnas. Cesare Mattei 
ja tema vend Giuseppe annetasid maavaldused paavstiriigile, et selle vägedel oleks parem organiseerida kaitset vaenlaste vastu. Tänutäheks annetas paavst Pius IX 1847. aastal neile krahvitiitli.

Bolognas osales Mattei rahvuskaardi loomises ja teenis välja koloneli auastme. Samuti valiti ta Itaalia parlamendi liikmeks. 1850. aastal omandas ta Grizzana Morandis, umbes 50 km kaugusel Bolognast kalju koos 12. sajandist pärinevate lossivaremetega. Ta rajas sinna mauri stiilis fantaasialossi (Rocchetta Mattei). 1859. aastal rajas ta lossitorni salajase laboratooriumi, kus hakkas tegelema alkeemiliste katsetega.

Anekdootlik lugu räägib, et Mattei avastas taimede ravitoime, kui ta nägi haiget hulkuvat koera, kes sõi erinevaid taimi ja kosus silmnähtavalt (Blessing 2011: 28; Lodispoto 1971). Sellele tuginedes lõigi ta taimedest koosnevad ravimpreparaadid, mis põhimõtteliselt aitasid kõikvõimalike haiguste korral. 1860. aastate alguses hakkas Mattei kuulsus levima ka laiema avalikkuse seas ning tema ravimeetodist hakati kirjutama ajakirjanduses. Arstid ja meditsiiniteadlased suhtusid tema meetodisse suure kahtlusega, kuid patsientide seas muutus see vägagi populaarseks (Stead 1892). Nii näiteks ravis ta Bolognas ajavahemikul 16. juulist 1865 kuni 15. oktoobrini 1867 kuni 20000 inimest. 1869. aastal andis paavst Pius IX tema käsutusse osa Santa Tereza hospitalist Roomas, kus ta sai patsiente vastu võtta ja tegeleda nende ravimisega. Pärast paavstiriigi okupeerimist Itaalia vägede poolt 1870. aastal tõmbus Cesare Mattei tagasi oma lossi. Tal keelati tegeleda Itaalias inimeste ravimise ja medikamentide müügiga, kuna tal puudus arstiharidus (Lodispoto 1971: 132).

1874. aastal avaldas ta oma esimese elektrohomöopaatiat käsitleva raamatu ("Un poco di storia sui rimedi Mattei"). 1880. aasta juulist hakkas ta välja andma ajakirja Bulletin de l'Electro-Homéopathie, hilisema nimega La Nouvelle Science Médicale, mis lõpuks ilmus nime Moniteur de l'Electro-Homéopathie all. Tema raamatud ja ajakiri levisid kogu Euroopas. Ravimite levitamiseks ja ekspordiks asutas Mattei Bolognasse kesklao, mida hakkas juhatama tema venna Giuseppe poeg Luigi Mattei, kes osutus aga ülimalt kehvaks ärimeheks. Mattei määras tema asemele oma kaastöölise Mario Venturoli (1858-1937), kelle ta 1888. aastal adopteeris. Saksamaal müüs Mattei oma ravimeid Regensburgis asuva ettevõtte Consortium für Electrohomöopathie kaudu (Helmstädter 1990: 35-37; Sahler 2003: 59).

19. sajandi lõpul levis elektrohomöopaatia ka Saksamaal, Prantsusmaal, Ühendriikides ja Inglismaal. Sajandivahetuseks oli ilmunud juba üle saja publikatsiooni, mis tutvustasid Mattei ravisüsteemi, välja anti kolme ajakirja (Baylen 1969). 1884. aastal oli kümnes Euroopa riigis kokku 79 müügikeskust. Venemaale jõudis elektrohomöopaatia teadaolevalt 1875. aastal (Facci 2017: 33). Eesti kohta on teada, et Tallinnas töötanud dr Alexander Rosendorff 
(1871-1963), kes oli Eesti tuntuim homöopaat, kohtus Matteiga ja oli kursis ka elektrohomöopaatiaga ning kasutas elektrohomöopaatilisi ravimeid (Jütte 2006: 37-38). 1920. aastatel pidas Rosendorff loenguid nii Tallinnas kui Tartus, kus muuhulgas käsitles ka homöopaatia ja elektrohomöopaatia erinevust (PM 1925).

20. sajandi alguses tarnis Bolognas asuv keskladu algtinktuure, mida kasutati ravimite valmistamiseks Regensburgis asuvale Engeli apteegile (Engel-Apotheke). Selline praktika kestis kuni Esimese maailmasõja alguseni. Kui varud ammendusid, hakkas apteeker Johannes Sonntag (1863-1945) koos elektrohomöopaatia eksperdi ja Mattei eluloo kirjutanud Theodor Kraussiga (1864-1924) valmistama originaalretseptile tuginevaid elektrohomöopaatilisi ravimeid. 1923. aastal loodi Engeli apteegi baasil JSO-Werk (Helmstädter 1990: 148-149).

Bologna ja Regensburgi vahelised läbirääkimised, mis algasid sõja lõpul, ei andnud tulemusi, ning Mario Venturoli-Mattei sõlmis lepingu Max Mandelbaumi (1888-1984) juhitud Adleri apteegiga Würzburgis, et see hakkaks Mattei elektrohomöopaatilisi ravimeid turustama kogu Saksamaal. Vaidlused kahe elektrohomöopaatiliste ravimite valmistaja vahel kestsid kuni 1930. aastani, mil lõpuks sõlmiti kokkulepe. Pärast Mandelbaumi emigreerumist Saksamaalt võttis äri üle Chemnitzis asuv Otto Stumpfi ettevõte. Pärast Teist maailmasõda turustas elektrohomöopaatilisi ravimeid, mida valmistas Bolognast imporditud algtinktuuridest, Hofis asuv kompanii Viropharm. Ravimite müük kestis kuni 1970. aastate lõpuni, mil krahvi pärijad lõpetasid algtinktuuride valmistamise. Viropharm müüs järelejäänud varud Adleri apteegile Würzburgis (Helmstädter 1990: 149).

\section{Ülevaade elektrohomöopaatilisest ravist}

Ravimeetodite otsimisel pöördub Mattei taimede poole: “Taimedest saavad söönuks loomad, taimede kaudu on loomariik seotud anorgaanilise maailmaga. Järelikult, ütlesin ma endale, on Jumal sinna paigutanud ka ravimid." (Mattei 1880: 10). Elektrohomöopaatilised ravimid jagunesid kahte gruppi: 27 tüüpi tahked pillid (tabel 1) ja viit tüüpi vedelikud (tabel 2). Ravimite nimetused tuletati nende toimest. Mattei kirjeldab väljatöötatud ravimeid järgmiselt (Mattei 1880: 54):

Inimese kehas leiduvad teatud kahjulikud lisandid või printsiibid, mida mõned kutsuvad herpetic, teised scrofulous ning mida Hahnemann kutsus psoric. Need printsiibid rikuvad keha organisatsiooni ja tekitavad eelsoodumuse reale haigustele. Kuid leiduvad vahendid nende eemaldamiseks, mida ma kutsun antiscrofulous. Need printsiibid kahjustavad 
lümfisooni, tuues kaasa lümfi koostise muutused. On ravimid, mida ma kutsun anticanceroso. Teistel juhtudel kahjustub vereringesüsteem, põhjustades muutusi veresoontes ning tekitades veenide ja arterite haiguseid. On olemas ravimid, mida ma kutsun anti-vaskulaarseteks, antiangioitic. Nende kolme tüüpi ravimitega saavad peaaegu kõik haigused ravitud, lisaks kasutab uus raviviis ka mõningaid teisi ravimeid: pectorals omab valikulist mõju bronhitorudele. Febrifuges ravib palavikke, muutuseid maksas ning põrnas. Vermifuges tapab sooleusse, nii naaskelsabasid kui paelusse ja trihhotsefaale. Antivenereal ravib kõiki sü̈̈flise vorme ja isegi aitab neid vältida.

Tabel 1. Tahked elektrohomöopaatilised ravimid.

\begin{tabular}{|l|l|l|l|}
\hline Tähistus & $\begin{array}{l}\text { Ravimigrupi } \\
\text { nimetus }\end{array}$ & Alagrupid & Toime \\
\hline S. & Antiscrofoloso & $\begin{array}{l}\text { S1, S2, S3, S4 S5, } \\
\text { S6 }\end{array}$ & Lümfisüsteemi puhastamine \\
\hline A. & Antiangioitico & A1, A2, A3 & $\begin{array}{l}\text { Vereringe puhastamine, } \\
\text { südame- ja } \\
\text { veresoonkonnahaigustele }\end{array}$ \\
\hline C. & Anticanceroso & $\begin{array}{l}\text { C1, C2, C3, C4, } \\
\text { C5, C6, C10, T.B. }\end{array}$ & $\begin{array}{l}\text { Nii hea- kui halvaloomulised } \\
\text { kasvajad, süüfilis }\end{array}$ \\
\hline F. & Febrifugo & F1, F2 & $\begin{array}{l}\text { Palavikud, neuralgia, } \\
\text { maksa- ja põrnahaigused }\end{array}$ \\
\hline Ver. & Vermifugo & Ver1, Ver2 & $\begin{array}{l}\text { Hävitab sooleusse, nii } \\
\text { naaskelsabasid kui paelusse } \\
\text { ja trihhotsefaale }\end{array}$ \\
\hline P. & Pectoral & P1, P2, P3, P4 & $\begin{array}{l}\text { Kõri- ja rindkerehaigused, } \\
\text { köha, katarr, bronhiit, } \\
\text { pleuriit, kopsupõletik }\end{array}$ \\
\hline Vüüfilis \\
\hline L. & Antivenerien & & \\
\hline
\end{tabular}

Tahketest ravimigruppidest on kolm kõige olulisemat antiscrofoloso, antiangioitico ja anticanceroso. Mattei kutsub neid esmasteks või tähtsaimateks ravimiteks, mille abil õnnestub ravida enamikku haigustest (Mattei 1891: 21).

Kahe ravimi (antiscrofoloso ja antiangioitico) abil taastatakse keha kõikide osade koostiselemendid normaalsesse seisundisse. Ühtlasi tõrjutakse välja kõik haigustekitajad ja taastatakse kahjustunud koed (Mattei 1880: 20-21). Samas kohtas Mattei ka juhtumeid, millede korral ei piisanud eelmainitud ravimitest, küll aga saavutati tervenemine siis, kui tarvitati kahte ravimit vaheldumisi 
(Mattei 1880: 12). Seega on olemas haigused, mis mõjutavad mõlemat süsteemi: lümfi kahjustamine mõjutab ka verd ja vastupidi.

Vedelaid ravimeid, mida Mattei nimetas elektrilisteks vedelikeks (electricità) oli viit tüüpi (tabel 2). Neid eristati värvi järgi: punane, roheline, valge, sinine ja kollane. Esialgu olidki vedelikud vastavat värvi, hiljem olid kõik vedelikud värvitud ja vastav värv kajastus vaid etiketi värvis. Elektrilisi vedelikke tarvitati peamiselt välispidiselt abistvate vahenditena, kuid neid võis tarvitada ka seespidiselt.

Tabel 2. Vedelad elektrohomöopaatilised ravimid.

\begin{tabular}{|l|l|l|}
\hline Nimetus & Tüüp & Toime \\
\hline Punane & positiivne & Stimuleeriv, maohaigused \\
\hline Kollane & negatiivne & Sooltehaigused, ussid \\
\hline Valge & neutraalne & Rahustava toimega \\
\hline Sinine & $\begin{array}{l}\text { sobib antiangioitico } \\
\text { tüüpi ravimitega }\end{array}$ & Verejooksude vastane \\
\hline Roheline & negatiivne & $\begin{array}{l}\text { Hävitab haiguste idusid, } \\
\text { antibiootilise toimega }\end{array}$ \\
\hline
\end{tabular}

Kuna Mattei leiutatud ravimid omasid sellist jõudu ja toimekiirust, mis lubas neid võrrelda elektrivooluga, siis nimetaski ta meetodi elektrohomöopaatiaks (Mattei 1880: 23; Mattei 1891: 9). Mingisugust muud seost elektrivooluga neil ei olnud. Selle rõhutamine on oluline, kuna hilisemad elektrohomöopaatia tõlgendused ja seletused seostavad ravimite toime taimse elektriga või bioenergiatega (Odyle energia, orgon energia, praana) (Ambrosi 2008; Facci 2017: 72-79; Kundu 2015). Ennemini meenutab Mattei ravimite toime van Helmonti kirjeldust väikesest kivist (lapillus), mille ta sai Iiri alkeemikult Butlerilt. Selle kivikese puudutamine keeleotsaga ravis kõiki haigusi, kusjuures kivi toime oli sarnane rästikumürgi toimega - kiire ja mõjus väikestes kogustes (Van Helmont 1652: 469, 474).

Mattei ettekujutuse järgi on inimkeha kompleksne tervik ja seega pole ka haigused lihtsad. Organsüsteemid töötavad seostatult ning kui ühes organis toimub häirimine või ilmneb tasakaalutus, siis mõjutab see ka teisi organeid ning viib sümptomite kompleksi ilmumisele. Seega tuleb kasutada seguravimeid, liitseid ravimeid, mis koosnevad erinevatest koostisosadest.

Harilik doos elektrohomöopaatilist ravimit on üks ravimiterake või tilk essentsi klaasi vee kohta. Samas kasutatakse ka kahekordset lahjendust ning mõnel harval juhul ka kolmekordset lahjendust. Harvadel juhtudel kasutatakse ka tugevamaid doose. Ravimi doos peab olema pöördvõrdelises seoses haiguse raskusega (Mattei 1880: 25). Tervenemine on seotud orgaanilis-vitaalsete reaktsioonidega, mis on esile kutsutud ravimite poolt ning need reaktsioonid 
on seda väiksemad, mida vähem on jäänud vitaalsust organismi endasse. Selle tõttu tuleb ka raskemate haiguste korral vähendada ravimi doosi. See on Mattei sõnutsi kooskõlas ka loodusseadusega, mis ütleb, et reaktsioon on alati täpselt võrdne ja vastupidine mõjuga (Mattei 1880: 26).

Inimesi huvitas omal ajal ja huvitab praegugi elektrohomöopaatiliste ravimite koostis. Mattei ise avaldas ainult nii palju: "Kõik need ravimid on eraldatud mittemürgistest taimedest, nagu on tõestanud kogemused ja analüüs." Kasutatavaid taimi ja nende töötlemise meetodeid hoidis ta saladuses. Etikettidele olid kantud vaid ravimi nimi, mis ei öelnud midagi selle koostise kohta (Facci 2017: 65-67). Esimesena kirjeldas elektrohomöopaatiliste ravimite valmistamist lähemalt Theodor Krauss, ${ }^{10}$ mainides spetsiaalset fermenteerimisprotsessi. Kraussi arvates kasutas Mattei Paracelsuse, Jan Babtist van Helmonti (1577-1644) ja Francois de le Boe Sylviuse (1614-1672) väljatöötatud iatrokeemilisi töötlemismenetlusi. Kraussi järgi toimus töötlemisprotsess järgmiselt. Kasutatavad taimed koguti sügisel või kevadel, kuna just sel ajal on taimemahlad eriti aktiivsed. Taimeosad purustati ja leotati (matsereeriti) destilleeritud vees 35 kraadi ("vere soojus") juures, kuni taimedest olid mahlad välja tulnud. Seejärel lisati uut taimemassi ja korrati protseduuri seni, kuni oli moodustunud "vedela mee" sarnase konsistentsiga vedelik. Krauss kutsub seda protsessistaadiumit küllastamiseks (saturation) ja kontsentreeritud matseraati "tinctura aquosa fortis" (tugev vesine tinktuur) (Krauss 1920: 58). Seejärel valati matseraat ilma õhu juurdepääsuta klaasnõusse, kus algas aeglane käärimisprotsess. Käärimise lõpuks oli põhja sadenenud taimemassi kohal selge, läbipaistev vedelik. See vedelik destilleeriti ning destillaat segati segamismasinas destilleeritud veega, suhkru ning puhta valge vaseliiniga. Saadud tainast vormiti peenikesed silindrid (it maddaleone), millest hiljem valmistati ravimipillid. Taimeekstraktid villiti pudelitesse (Facci 2017: 69).

Midagi enamat preparaatide valmistamise kohta teada ei olegi. Osaliselt on säilinud Mattei laborisisustus - uhmer, segamismasin, taimepress ja destillaator ning graanulite valmistamise seade (Facci 2017: 68-70). Hiljuti avaldatud Mattei käsikirjalistest märkmetest on siiski selgunud ka mõned üksikasjad tema preparaatide koostise kohta (Facci 2017: 36-55). Ta kasutas 32 täiesti tavalist taime: mänd, plaatan, harilik altee, küüslauk, sibul, kadakas, aedpihlakas, leeder, asparaagus, kreeka pähkel, uba, kapsas, viirpuu, harilik apteegitill, kanepiseemned, leetpõõsas, luuderohi, pirn, kibuvits, linaseemned, petersell, uimastav raihein, kiinapuu koor, nisu, laukapuu, salvei, viinapuu, aedruut, samblikud, rosmariin, apelsinikoor, kirss. Nimetatud taimedest kasutatakse lehti, vilju, juuri, õisi, sibulaid, koort, seemneid. Ainsaks kasutatud loomseks aineks oli searasv. 
Ravimid koosnesid üldjuhul ravimtaimede segudest, näiteks koosnes Antiscrofoloso (S1) võrdsetest osadest luuderohulehtedest, linaseemnetest, kanepiseemnetest, leedriõitest ja kahekordest kogusest pirnilehtedest, -õitest ja -viljadest. Punane electricità sisaldas kreeka pähkli lehti, valge electricità pirnilehti, -õisi ja -vilju ning sinine electricità aedpihlaka lehti ja koort, kibuvitsa marjasid ja viirpuu õisi ning vilju. (Facci 2017: 57)

Erinevate taimeosade kasutamine on jällegi meditsiinilises alkeemias vägagi tavaline. Nii rõhutab juba Paracelsus: "Kui nüüd alkeemik asub uurima, mis looduses peitub, siis tuleb teada, et erinevates asjades varjuvad erinevad jõud: ühed pungades, teised lehtedes, kolmandad õites, neljandad toorestes viljades, viiendad küpsetes viljades; ..." (Paracelsus 1998: 76).

Mattei käsitleb enda loodud elektrohomöopaatiat klassikalise Samuel Hahnemanni (1755-1843) homöopaatia edasiarendusena. Mõlemad ravimeetodid tuginevad sarnasuse printsiibile, mille kohaselt mingi haiguse ravimitena kasutatakse selliseid aineid, mis põhjustavad tervel inimesel antud haigusele omaseid sümptomeid. Samas rõhutab Mattei kasutatavate ravimite, nende toime ja kahe lähenemise teoreetiliste aluste suurt erinevust (Mattei 1880: 21). Homöopaatiline ravi piirdub eluohtlike haiguste korral vaid nähtavate ilmingutega, ilma et see jõuaks tegelike põhjusteni. See omakorda tähendab seda, et haigus ilmub mingi aja pärast uuesti. Seega ei suuda homöopaatia ravida eluohtikke haiguseid. Sellel lisandub veel väga suur ravitavate sümptomite arv, mis muudab diagnoosimise ja sobiva ravimi leidmise keerukaks (Mattei 1880: 22). Mattei loodud elektrohomöopaatia tugineb küll homöopaatiale, kuid on selle arendamine hoopis uuele tasemele. Klassikaline ehk Hahnemanni õpetusi järgiv homöopaatia kasutab ühte toimeainet sisaldavaid ravimeid. Sellest klassikalisest lähenemisest erinevad nn komplekshomöopaatilised suunad, mis kasutavad liitravimeid. Elektrohomöopaatia kuulubki komplekshomöopaatia suunda. Elektrohomöpaatia kolm põhilist erinevust homöopaatiast ongi järgmised. Esiteks, ei järgita täielikult sarnasuse seadust. Teiseks, ei kasutata raviaine järjestikuse lahjendamise protseduuri toime tugevdamiseks. Kolmandaks, ravimeid ei katsetata alguses mitte tervetel inimestel, nagu homöopaatias, vaid alustatakse haigetega.

Kuna elektohomöopaatia kasutab kompleksseid ravimeid ja eirab mitmeid homöopaatia teisigi reegelid, ei tunnistanud Homöopaatia keskühing (Central Homoeopathic Association) seda homöopaatilise ravimeetodina ning leidis, et kasutatavad ravimid ei ole vastavuses Hahnemanni õpetusega. ${ }^{11}$ 


\section{Elektrohomöopaatia kui iatrokeemia jätk 19. sajandil}

Mattei nimetab oma käsitlust mitte lihtsalt uueks meditsiinisüsteemiks, vaid lausa uueks teaduseks: “...ma saavutasin revolutsiooni meditsiinis. Ma pärandan maailmale mitte meditsiinisüsteemi, vaid meditsiini, mida pärast 25 sajandit oli vaja veel otsida. Juba pikka aega olen ma teadnud väga hästi kõikide süsteemide tühjust mida iga sajand ja peaaegu iga koolkond on pookinud mädanenud meditsiiniteaduse puu vanale tüvele" (Mattei 1880: 2, 13-14). Ta tunnistab, et pole ise arst, aga sellele vaatamata kritiseerib armutult kaasaegset meditsiini: "Olemata küll ise arst, sain ma lihtsal viisil aru, et meditsiinikoolide poolt pakutav on jõuetu ka kõige väiksemate hädade korral, kuigi samal ajal toimub teaduse paraaditsemine" (Mattei 1880: 2). Tegemist on uue leiutisega, uue asjaga, mis on parem kui kõik eelnenu. Siinkohal võib jällegi tõmmata selge paralleeli Paracelsusega, kes samuti rõhutas oma käsitluste erinevust kõigest varasemast: "Siin, selles teoses ma tutvustan uut Theoricam, mis on samuti Physicam, koos uute kontseptidega, mida senini pole kunagi teatud, ega ole neid mõistnud filosoofid, astronoomid, ega arstid..." (Paracelsus 1996: 12).

Mattei stiil ja keel on üsna sarnased Paracelsuse omadele, eriti nendes lõikudes, kus ta ründab arste ja ülikoole ning kogu senist meditsiini laiemalt. Mattei väidab kindlalt, et: “Teadusmehed võivad mitte üksnes olla vastuspidisel arvamusel kui mina, nad võivad ka võidelda, lükata tagasi ja isegi naeruvääristada mu teoreetilisi ideid, kuid neil ei ole õigus lükata tagasi silmanähtavaid ja vaieldamatuid fakte" (Mattei 1880: 21).

Mattei rõhutab igati oma süsteemi empiirilist alust. Erinevalt kõikidest senistest meditsiinisüsteemidest põhineb elektrohomöopaatia praktilisel ravimisel ja teooria tuletatakse ainult kogemusest. Tähtis on see, et ravim aitaks haiget, kõik muud aspektid on teisejärgulised. Ta toonitab seda, et vaatamata teaduse edusammudele haiguste põhjuste kindlakstegemisel ja patoloogiate kirjeldamisel ei suuda tavameditsiin haigusi ravida. Tema käsitluse kohaselt seisneb meditsiin ravimises: "Meditsiiniteadus on kõrgemal keemiast ja füüsikast; see on tervendamise kunst; ma esitan järgmise paradoksi: On vajalik, et arst mõtleks mitte ainult patsientide uurimisest, vaid mõtleks nende ravimisest" (Mattei 1880: 4-5).

Mattei rõhutab korduvalt, et elektrohomöopaatia sündis esmalt kui ravimeetod ja alles hiljem jõudis ta kogemuste üldistamise teel selle toimemehhanismi selgitamisele. Esmalt alustas ta ravimisega, mis ongi tõelise meditsiini tegelikuks ülesandeks, ja alles siis jõudis teooria ja ravitoime seletamiseni. Kusjuures viimased pole elektrohomöopaatias kunagi kesksel kohal, erinevalt jällegi tavameditsiinist. Mattei väitis, et kõik varasemad meditsiinisüsteemid on võtnud vale kursi: "Sest nad otsivad ravimeid pärast ideede väljamõtlemist, 
et tõestada juba olemasolevat teooriat, selle asemel, et alustada materia medica katsetamisega ja luua teooria alles pärast seda" (Mattei 1880: 14). Paracelsus (1996: 73-74) rõhutab samuti kogemuse ja reaalse ravi olulisust: "Kogemus on sellisena loodud, et selle toimimine on mõistetav igaühele ilma suurema lobata. Just sel põhjusel tuleb rohkem tähelepanu pöörata praktikale, et saada aru, mis see on."

Pärast mitmeid aastaid edukat ravimist jõudis Mattei järgmisele järeldusele: "Kui ma olin suuteline alistama tuhandeid kõige erinevamal kujul esinevaid lümfaatilisi haiguseid antiscrofoloso abil: nagu ma olen ravinud lõpmatu hulga veresoonte haiguseid antiangioitico abil: sai minu jaoks aksioomiks (aksioomiks, mis tugineb alati samadele ja paljude aastate jooksul igapäevaselt tähendatud faktidele), et antiscrofoloso on kindel ravim lümfi jaoks, samuti nagu antiangioitico on kindel ravim vere jaoks, ja et meie kõigi haiguste põhjused on taandatavad ainult neile kahele" (Mattei 1880: 12).

Mattei tegi siit järelduse, et haigustel, mida saab ravida sama ravimiga, on ühine põhjus ja selleks ühiseks põhjuseks on kas vere või lümfi kahjustumine. Kõik organismi talitlused on taandatavad verele ja lümfile. Vere- ja lümfisüsteem kannavad kõikidesse kehaosadesse neid toitvaid vedelikke, vastavalt siis verd ja lümfi. Veri on läbitöötatud ja oksüdeeritud lümf (Mattei 1880: 18). Toidust selle lagundamise ja töötlemise tulemusena saadud vedelik satub küülusesoontesse ja sealt lümfisoontesse, seejärel seguneb punase verega ja liigub südamesse, sealt edasi kopsudesse, kus see oksüdeerub punaseks vereks. Veri kannab toitaineid kõikidesse kudedesse ning oksüdeeritud veres leiduv hapnik põletab ära oma rolli täitnud ja vananenud kehaosakesed, mis seejärel eemaldatakse naha, hingamiseelundite, neerude jne kaudu (Mattei 1880: 18-19). Veri ja lümf omandavad kehale kasulikke aineid seedesüsteemis: "Lõpuks veri ja lümf, mis tsirkuleerivad täiesti eraldatud soontesüsteemides, omavad ühtset päritolu seedimise laboratooriumist, mis toodab lakkamatult aineid, mis moodustavad elu säilitamiseks vajalikke osasid" (Mattei 1880: 63-64). Seedimise kui keha keskse laboratooriumi rõhutamine ulatub jällegi tagasi vähemalt kuni Paracelsuse töödeni. Paragranumis kirjutab ta järgmiselt: "Siin tulebki mängu juhtimine; kui sa mingi ravimi sisse annad, siis peab magu selle valmis tegema; tema ongi alkeemik" (Paracelsus 1998: 69).

Lümf ja veri kuulusid koos kollase ja musta sapiga humoraalmeditsiinis kesksel kohal olevate kehamahlade hulka. ${ }^{12}$ Kuigi iatromeditsiin proovis ennast humoraalmeditsiinist "lahti haakida", siis üle kandusid mitmed nii kehavedelike kui ka keha temperamenditüüpidega seotud ideed. Nii näiteks omistas Sylvius haiguste, ennekõike kasvajate, tekkel olulise koha lümfile (de Moulin 1983: 21-22). Kehavedelike, ennekõike vere ja lümfi liikumise olulisust kehas rõhutas näiteks Friedrich Hoffmann (1660-1742), kes oli iatromehaanika 
suuna esindaja. ${ }^{13}$ Mattei väidab ise, et kasutab kaasaegse teaduse tulemusi oma teooria selgitamiseks ja kinnitamiseks (Mattei 1880: 20).

Kuna kõik haigused taandusid vere või lümfi kahjustustele, siis ei ole haiguse esinemisvorm või asukoht piisavad, et valida õige ravim. Nii näiteks on nahahaigustel väga erinevaid vorme ja need võivad esineda kehal erinevates kohtades. Ometigi on alati tegemist lümfisüsteemi häirega (Mattei 1880: 15-16). Kuna ravimid koosnesid mitmetest ainetest, siis sai organism ise välja valida just need, mis olid tervenemiseks vajalikud. Need ained, mida otseselt vaja ei ole, ei mõjuta organismi ning neil ei ole seega ei kasulikku ega kahjulikku toimet. Tänu komplekssele koostisele mõjuvad ravimid üheaegselt erinevatele haigestunud organsüsteemidele ja Mattei sõnutsi likvideerivad nii haiguste sümptomid kui ka põhjused (Mattei 1884: xi; Mattei 1891: 5-6).

Elektrohomöopaatiliste ravimite toimes ei olnud midagi maagilist ega imepärast. Ravimite loomulikku toimet toob korduvalt esile ka Mattei ise. Üks väga iseloomulik ja huvitav episood on leidnud kajastamist ka kirjanduses. Vastates paavst Pius IX küsimusele oma ravimite lausa imepärase toime kohta ütles Mattei: "Teie Pühadus! Pühaku ja minu vahel on suur erinevus, minu ravimid on vaid materiaalsed ja looduslikud" (Facci 2017: 78). Paracelsus rõhutas samuti oma ravimite päritolu ja seost loodusega ning rõhutas ravimite toime loomulikku aspekti. Näiteks teoses Herbarius kirjeldab ta kirburohu võimet ravida lahtiseid haavu järgmiselt: “...võtke taim ja kastke see voolavasse vette. Seejärel asetage see vigastusele, mida soovite ravida ning hoidke seda seal umbes sama kaua kui kulub poole muna söömiseks. Seejärel matke taim maha niiskesse kohta, kus see laguneb. Sellisel viisil muutub haav terveks. Kui ma räägin teile, et mõned inimesed teevad haava kohal risti ja teised lisaks ka palvetavad, pean ma lisama, et sellised asjad ei ole vajalikud. Need ei kuulu ravi juurde, kuna seal on loomulikult, mitte üleloomulikult või maagiliselt toimiv mõju" (Moran 1993: 111).

Taimede kasutamine ravimite valmistamiseks oli omane juba galeenilisele farmaatsiale, iatrokeemia arendas edasi taimedest aktiivsete ravimite keemilise eraldamise meetodeid (Kalling 2017: 104-105). Mattei kasutas iatrokeemiale omaseid võtteid taimematerjali töötlemiseks. Alkeemiale omaselt ei ole olemas ühte kindlat taimsete ravimite valmistamise viisi. Iga alkeemik töötab välja oma, individuaalse, tõsi küll üldistele printsiipidele toetuva, meetodi ravimite valmistamiseks. Seda individualiseeritust on hästi näha elektrohomöopaatia arengus pärast Mattei surma, mil kujunesid välja erinevad lähenemised ja võeti sama nime all kasutusele hoopiski erinevate koostistega ravimid (Facci 2017: 83-112). Kindlasti olid omal kohal ka majanduslikud kaalutlused - head, sissetöötatud kaubamärki ei saanud jätta kasutamata, kuigi ravimite täpsed koostisosad ja valmistusmeetodid olid teadmata. 


\section{Elektrohomöopaatia tänapäeval}

Huvi alternatiivsete ravimeetodite vastu ei ole tänapäeval sugugi vähenenud ja nii pole ka elektrohomöopaatia kuhugi kadunud. Itaalias Bolognas asub Cesare Mattei arhiivmuuseum (Archivio Museo Cesare Mattei), mis tegeleb Mattei pärandi uurimise ja tutvustamisega.

Tänapäeval on elektrohomöpaatia levinud kõige enam Indias. Leviku üheks toetavaks asjaoluks on kindlasti Indias kuni tänase päevani püsinud alkeemilised traditsioonid - ajurveda meditsiin ja Lõuna-Indias levinud siddha meditsiin. Indiasse tõi elektrohomöopaatilised ravipraktikad jesuiit Keith Augustus Müller (1841-1910), kes töötas Mangalore leprosooriumis. Indiasse saabus ta Pariisist 1878. aastal, kaasas homöopaatilised ravimid. 1880. aastal avas ta vaeste homöopaatilise dispanseri, kus ravis inimesi tasuta homöopaatiliste ravimitega. Hiljem arendas ta sellest välja püha Joosepi nimelise leeprahaigla ja varjupaiga. Ta katsetas erinevate homöopaatiliste raviviisidega, kuni töötas välja oma, India tingimustesse sobivaima süsteemi. Tänaseks on samast asutusest kujunenud üks India suurimaid homöopaatia õppe- ja uurimiskeskusi (Chand 2007).

Saksamaal 1920. aastate alguses loodud ettevõttest JSO-Werk, mis tegeles algselt Mattei ravimite müügiga, on tänapäevaks kujunenud spagüürilisi ravimeid tootev firma JSO Arzneimittel. Ettevõte kasutab Mattei kaastöölise Theodor Kraussi (1864-1924) poolt kasutuselevõetud ravimiretsepte (JSOKomplex-Heilweise) (Helmstädter 1990: 148-149). 1925. aastal asutatud ettevõtte PHÖNIX-Laboratorium (Bondorfis) spagüürilised preparaadid põhinevad Mattei toetaja ja elektrohomöopaatia populariseerija Johann Conrad Glückseligi (1864-1934) retseptidel, Glückselig toetus Paracelsuse õpetusele (Krebs 1984).

Lisaks müüakse elektrohomöopaatilisi ravimeid ka Suurbritannias, Saksamaal, Kanadas ja USAs.

\section{Kokkuvõte}

Mattei tugines on ravisüsteemi loomisel nii homöopaatiale kui ka varasemale alkeemilisele traditsioonile. Samas võttis ta üle kaasaegse teaduse ideid ja integreeris neid oma ravisüsteemi. Elektrohomöopaatia on iatrokeemia edasiarendus, tuginedes selgelt oma aja teadustele, ning selles ei ole midagi müstilist ega okultset. Elektrohomöopaatia iseloomustab väga hästi tõsiasja, et alkeemia praktikad ja teooriad muutusid aja jooksul ja kohandusid muutunud kontekstidega. Tegemist on selle väljatöötaja sõnutsi empiirilise ravisüsteemiga, mille korral on väidetavalt esmane ravimite toime katsetamine ja alles selle alusel 
teooria püstitamine. Tänapäeva elektrohomöopaatiat iseloomustab kasutatavate ravimprepraatide rohkus ja müstiliste seletuste kasutuselevõtt.

\section{Kommentaarid}

1 Alkeemia tähenduse ja teaduslikkuse ümberhindamise kohta vt nt Principe 2013; Moran 2005; Newman 2004; Principe \& Newman 2001.

2 Olulisematena tuleks mainida järgmisi töid: Blessing 2011; Helmstädter 1990; Lodispoto 1968 ja Lodispoto 1971.

3 India alkeemia kohta vt White 1996.

${ }^{4}$ Kreeka keelest iátoós (iatrós) - arst, meditsiin.

5 Ramon Llull (ligikaudu 1232-1315) oli omaaegne universaalne õpetlane, kes tegeles matemaatika, filosoofia, loogika ja kirjandusega. Esialgu elas ta rikka aadlimehe elu Mallorca Kuningriigis, pärast religioosse ilmutuse saamist aga astus frantsiskaani ordusse. Ta oli peaaegu 300 teose autor. Keskajal ja renessanssiajal omistati Llullile aga suur hulk erinevate autorite peamiselt hermeetilise ja alkeemilise sisuga tekste. Selle tekstikorpuse fiktiivset autorit tuntakse pseudo-Llullina.

6 Terminit "spagyria" või ka "ars spagyria" kasutab Paracelsus oma raamatus "Liber Paragranum”. Vt ka Burckhardt 1972: 20.

7 Kasutatakse ka nimekuju Franciscus de le Boë Sylvius.

$8 \mathrm{~N}$-ö tavameditsiinis kasutatavaid ravimeid, millede toime on vastupidine sümptomitele, kutsutakse homöopaatias allopaatseteks ravimiteks (kreeka alloin - erinevad).

9 Mattei eluloo kohta vt Helmstädter 1990: 19-34; Jütte 1996: 229-234 ja Mattei 1880.

${ }^{10}$ Krauss tundis Matteid ja tegeles ise aktiivselt elektrohomöopaatiaga. Lähemalt vt Krauss 1920: 56-66.

${ }^{11}$ Otsus elektrohomöopaatia mittetunnustamise kohta tehti Homöopaatia keskühingu 47. aastakoosolekul Hannoveris 1879. aastal.

${ }^{12}$ Humoraalteooria kohta vt Kalling 2017: 69-75.

${ }^{13}$ Iatromehaanika või iatrofüüsika rõhutas organismides toimuvaid mehaanilisi protsesse, pidades neid esmasteks, omistades keemilistele nähtustele sekundaarse rolli.

\section{Kirjandus}

Ambrosi, Fabio 2008. Electro-Homoeopathy: some lights between history and legend. Some Lights on Electro-Homoeopathy - Between History and Legend. International Historical-cultural Conference on count Cesare Mattei and Electrohomeopathy. Saturday 20th and Sunday 21st september 2008, Porretta Terme (Bologna), Italy (http://www. erdoindia.org/articles/downloads/Dr\%20Fabio\%20Ambrosi.pdf - 19. oktoober 2020). 
Bacon, Roger 1597. The mirror of alchimy. London: Printed for Richard Oliue (https:// ia800500.us.archive.org/35/items/mirrorofalchimy00baco/mirrorofalchimy00baco.pdf19. oktoober 2020).

Baylen, Joseph O. 1969. The Mattei Cancer Cure: A Victorian Nostrum. Proceedings of the American Philosophical Society 113 (2), lk 149-176.

Blessing, Bettina 2011. Pathways of Homoeopathic Medicine. Complex Homoeopathy in its relationship to homoeopathy, naturopathy and conventional medicine. Heidelberg: Springer Medizin Verlag.

Burckhardt, Titus 1972. Alchemy: Science of the Cosmos, Science of the Soul. Baltimore: Penquin Books Inc.

Chand, Divan Harish 2007. History of Homoeopathy in India in the $19^{\text {th }}$ Century. New Delhi: B Jain Publishers Pvt Ltd.

Debus, Allen G. 2002. The Chemical Philosophy. Paracelsian Science and Medicine in the Sixteenth and Seventeenth Centuries. Mineola, New York: Dover Publications Inc.

Facci, Mario 2017. I segreti dell elettromeopatia del Conte Cesare Mattei. Libreria Piani.

Hedesan, Georgiana D. 2016. An Alchemical Guest for Universal Knowledge: The Christian Philosophy' of Jan Baptist Van Helmont (1579-1644). London and New York: Routlege.

Helmont, Jan Baptist van 1652. Ortus medicinae, id est, initia physicae inaudita, ed. 2. Amsterdam: Elzevir.

Helmstädter, Axel 1990. Spagyrische Arzneimittel: Pharmazie und Alchemie der Neuzeit. Stuttgart: Wissenschaftliche Verlagsgesellschaft mbH.

Jütte, Robert 1996. Geschichte der Alternativen Medizin. Von der Volksmedizin zu den unkonventionellen Therapien von heute. München: Beck.

Jütte, Robert 2006. The Hidden Roots: A History of Homeopathy in Northern, Central and Eastern Europe. Stuttgart: Institute for the History of Medicine of the Robert Bosch Foundation.

Kahn, Didier 2007. Alchimie et paracelsisme en France (1567-1625). Geneva: Droz.

Kalling, Ken 2017. Meditsiini ajalugu. Tartu: Tartu Ülikool.

Krauss, Theodor 1920. Die Grundgesetze der Elektro-Homöopathie oder zusammengesetzten homöopathischen Complex-Heilmethode: System des Grafen Cesare Mattei. Regensburg u Leipzig.

Krebs, Harald 1984. Entgiftung durch spagyrische Mittel. Bondorf: Phönix-Laboratorium-GmbH.

Kundu, Debasish 2015. Spagyric Homeopathy or Electro Homeopathy. International Journal of Homeopathy \& Natural Medicines 1 (1), lk 1-6 (doi: 10.11648/j. ijhnm.20150101.11).

Lodispoto, Alberto 1968. Conte Cesare Mattei el'Elettromiopatia. Atti del XXI. Congresso internazionale di Storia della Medicina, Bd. 2, Siena, lk 1126-1132. 
Lodispoto, Alberto 1971. L'Elektromiopathie du Comte Cesare Mattei. Acta Homeopathica 15, lk 130-134, 210-215.

Mattei, Cesare 1880. Electro-homeopathy: The principles of new science. Bologna: The Printing Office Mareggiani.

Mattei, Cesare 1884. Elektro-homöopathische Arzneiwissenschaft oder neue auf Erfahrung begründete Heilkunde. Herausgegeben von Mario Venturoli Mattei. Regensburg: Verlag: Georg Joseph Manz.

Mattei, Cesare 1891. Electro-homeopathic medicine: a new medical system. London: David Stott.

Matus, Zachary A. 2017. Franciscans and the Elixir of Life: Religion and Science in the Later Middle Ages. Philadelphia: University of Pennsylvania Press.

Moran, Bruce T. 1993. The "Herbarius" of Paracelsus. Pharmacy in History 35 (3), lk 99-127.

Moran, Bruce T. 2005. Distilling Knowledge: Alchemy, Chemistry and the Scientific Revolution. Cambridge, MA: Harvard University Press.

Moulin, Daniel de 1983. A short history of breast cancer. Dordrecht: Springer Science+Business Media.

Multhauf, Robert 1956. The significance of distillation in Renaissance medical chemistry. Bulletin of the History of Medicine 30, lk 329-346.

Newman, William R. 2004. Promethean ambitions: Alchemy and the quest to perfect nature. Chicago: The University of Chicago Press.

Paracelsus 1996. Four treatises of Theophrastus von Hohenheim called Paracelsus. Baltimore and London: The John Hopkins University Press.

Paracelsus 1998. Paragranum. Akadeemia 10 (1), lk 64-88.

PM 1925 = Femina estona. Veel kord homöopaatiast. Postimees 180, 8. juuli 1925, lk 5 (https://dea.digar.ee/cgi-bin/dea?a=d\&d=postimeesew19250708.2.25-4. oktoober 2020).

Principe, Lawrence M. 2013. The secrets of alchemy. Chicago \& London: The University of Chicago Press.

Principe, Lawrence M. \& Newman, William R. 2001. Some problems with the historiography of alchemy. William R. Newman \& Anthony Grafton (toim). Secrets of nature: astrology and alchemy in early modern Europe. Cambridge: MIT Press, lk 385-431.

Sahler, Andrea M. 2003. Homöopathische Komplexmittel: ihre historische Entwicklung, ihre Begründer und ihre gegenwärtige Bedeutung. München, Bad Kissingen, Berlin: Richard Pflaum Verlag GmbH \& Co. KG.

Stead, W[illiam] T[homas] 1892. Can cancer be cured? Report of the Mattei Investigation Committee. Review of Reviews 6 (2), lk 195-196.

White, David Gordon 1996. The alchemical body: Siddha traditions in medieval India. Chicago and London: The University of Chicago Press. 


\title{
Summary
}

\section{Medical alchemy in the 19th century: Theoretical and practical foundations of electrohomeopathy}

\author{
Kurmo Konsa \\ Professor \\ Pallas University of Applied Sciences, Estonia \\ Associate Professor \\ Department of Archival Studies, University of Tartu, Estonia \\ kurmo.konsa@ut.ee
}

Keywords: alchemy, Cesare Mattei, electrohomeopathy, herbal therapy, medical alchemy, spagyric

Medical alchemy emerged within the Western alchemical tradition in the 13th-14th centuries. However, well-established medical alchemy can be considered the iatrochemistry of the 16 th century. In this article, I focus on the continuation of the alchemical tradition in the second half of the 19th century, using the electrohomeopathy created by Cesare Mattei as an example. Electrohomeopathy, also known as Mattei's treatment of cancer or Matteism, is a form of homeopathy developed by Count Cesare Mattei (1809-1896) in the second half of the 19th century.

Because the drugs invented by Mattei had such strength and rate of action that allowed them to be compared to electric current, he called the method electrohomeopathy. They had no other connection to electricity. It is important to emphasize this again, as later interpretations and explanations of electrohomeopathy link the effects of drugs to plant electricity or bioenergy (Odyle energy, organ energy, prana).

Electrohomeopathy created by Mattei is based on homeopathy, but he thought it was in need of further development. In his electrohomoeopathy he saw a great reformation of homoeopathy. Mattei acknowledged Hahnemann's similarity principle while criticizing his doctrine because it used, as he said, only remedies that were not combined and only addressed the symptoms. Like complex homoeopaths he thought that the use of single remedies was a mistake that held back the development of homoeopathy. Mattei relied on both homeopathy and an earlier alchemical tradition in creating the treatment system. At the same time, he took over the ideas of contemporary science and integrated them into his treatment system. Electrohomeopathy is a further development of iatrochemistry, clearly based on the science of its time, and has nothing mystical or occult in it. Electrohomeopathy is very well characterized by the fact that alchemical practices and theories changed over time and adapted to changed contexts. According to its developer, this is an empirical treatment system, which says that the first step is to test the effects of drugs and to establish a theory on that basis. Modern electrohomeopathy is characterized by an abundance of drugs used and the introduction of mystical explanations. 
Kurmo Konsa on Tartu Ülikooli ajaloo ja arheoloogia instituudi arhiivinduse osakonna kaasprofessor ja Kõrgema Kunstikooli Pallas professor. Ta on lõpetanud Tartu Ülikooli bioloogia erialal ja Tallinna Ülikooli raamatuteaduse erialal. Tal on doktorikraad infoteaduses Tallinna Ülikoolist.

Kurmo Konsa is Associate Professor at the Department of Archival Studies at the University of Tartu, and Professor of Conservation at Pallas University of Applied Sciences. He has an MSc in microbiology from the University of Tartu, and an MA in book science from Tallinn University. Kurmo Konsa holds a PhD in informational science from Tallinn University. His $\mathrm{PhD}$ thesis focuses on the preservation of written heritage and conservation issues. In the past he worked at the University of Tartu Library as a paper conservator and at the Estonian Postal Museum as conservator and curator of collections.

kurmo.konsa@ut.ee 